The BMJ

eloder@bmj.com Follow Elizabeth on Twitter @eloder

Cite this as: $B M / 2022 ; 376: 0470$ http://dx.doi.org/10.1136/bmj.0470

Published: 24 February 2022

\section{Progress against health inequities is slow and obstacles are numerous}

\section{Elizabeth Loder head of research}

According to the non-profit think tank Global Health Europe, "health inequities are unfair, avoidable differences arising from poor governance, corruption or cultural exclusion" (https://global-

healtheurope.org/values/inequity-and-inequality-inhealth). ${ }^{1}$ The World Health Organization's Commission on Social Determinants of Health likewise identifies "poor social policies and unfair economic arrangements" as key causes of inequities and lack of progress in addressing social determinants of health (doi:10.1136/bmj-2021066172). ${ }^{2}$

One reason for slow progress in reducing health inequities is the challenge of producing doctors who reflect the cultural, racial, and ethnic backgrounds of the patients they serve. We have ample evidence that such patient-doctor concordance is associated with improved health outcomes. For example, one element of diagnostic excellence is avoiding cultural biases such as racism (doi:10.1136/bmj-2021-068044). ${ }^{3}$ This goal is more likely to be achieved by clinicians who come from diverse backgrounds and train and work in diverse settings. Why, then, are new private medical schools in the UK admitting well-off students from other countries rather than offering places to UK students from diverse backgrounds and underserved areas such as the north west of England (doi:10.1136/bmj.0421)? ${ }^{4}$ The schools' professed common goal of admitting those from

under-represented backgrounds has been subverted by the practical need for tuition money.

This is arguably the result of poor governance and social policy, with the dean of one new school citing a lack of domestic funding for the schools and a UK Treasury that is "basically dragging its feet." Perhaps it is not surprising, then, to learn that the UK government also has been unable to develop and fund a workforce plan to improve the recruitment and retention of healthcare staff

(doi:10.1136/bmj.0422). ${ }^{5}$ The shortage of healthcare workers is a longstanding problem made even worse by the pandemic (doi:10.1136/bmj.0386). ${ }^{6}$

We need not look far to find differences in health outcomes that can be attributed to cultural exclusion. A big proportion of UK maternal deaths due to suicide or substance abuse could have been prevented by better care, one national review concluded (https://www.npeu.ox.ac.uk/assets/downloads/mbrrace-uk/reports/maternal-report-2021/MBRRACEUK_Maternal_Report_2021_-_FINAL_-_WEB_VERSION.pdf). ${ }^{7}$ Despite this, the contribution of stigmatised mental health conditions to maternal illness and death after delivery is largely ignored. This has an outsized impact on black women, who are four times as likely as white women to die in the perinatal period (doi:10.1136/bmj-2021-069486). ${ }^{8}$
Clinically vulnerable people-those with cancer or immune deficiencies, for example-have also been ignored and "left out of the best parts of life by a government and some parts of society who think we all just need to 'get on with it'"

(doi:10.1136/bmj.0397). ${ }^{9}$ They have no right to work from home despite uncertain protection from covid vaccination and an increased risk of death or serious illness should they contract the disease. Many must choose between continued isolation and absence from normal activities and accepting an increased risk of infection as mask mandates and vaccination requirements are loosened or dropped.

The news is not all bleak, however. In a $B M J$ special paper, Tang and colleagues report on the development and validation of a model to predict clinical deterioration in patients admitted to hospital with covid-19 (doi:10.1136/bmj-2021-068576). ${ }^{10}$ The novelty of the paper is not the algorithm but rather the methods used to create it. The machine learning model is open source. It was developed using data from patients admitted to hospital from 2015 to 2019 for respiratory distress in a large US health system, and then internally validated using data from patients admitted with covid-19 in the same health system. Then the model was applied at 12 other health systems, using the open source computer code. The code was transferred, not patient data, so no time was wasted waiting for negotiation of complex data sharing agreements. This is a secure and highly efficient federated rather than centralised approach to model validation and one that facilitates the development of models that work well in different populations.

Among other things, the medical centres that applied the model were able to test its performance in their particular mix of ethnic, racial, age, and other patient subgroups. Such evaluation of model performance in different patient populations is crucial to ensuring that risk models provide useful, accurate information for all groups, yet it is often overlooked. The speed with which this model was developed and tested is a pleasant contrast to the slow progress of other approaches.

Global Health Europe. Inequity and inequality in health. 2009. https://globalhealtheurope.org/values/inequity-and-inequality-in-health. Gopinathan U, Buse K. How can WHO transform its approach to social determinants of health?BMJ2022;376:e066172. doi: 10.1136/bmj-2021-066172 pmid: 35135754

3 Singh $\mathrm{H}$, Connor DM, Dhaliwal G. Five strategies for clinicians to advance diagnostic excellence. BMJ2022;376:e068044. doi: 10.1136/bmj-2021-068044 pmid: 35172968

4 Wilkinson $E$. The real reason that new UK medical schools are focusing on international students. BMJ 2022;376:0421

5 Waters A. Government "missed opportunity" to tackle NHS and social care staff shortages. BM/2022;376:0422. doi: 10.1136/bmj.0422 pmid: 35177489 Murray R. Recovery plan for elective care. BMJ2022;376:0386. doi: 10.1136/bmj.0386 pmid: 35177438 
7 Knight M, Bunch K, Tuffnell D, et al. Saving lives, improving mothers' care: lessons learned to inform maternity care from the UK and Ireland confidential enquiries into maternal deaths and morbidity 2017-19. National Perinatal Epidemiology Unit, University of Oxford. 2021.

https://www.npeu.ox.ac.uk/assets/downloads/mbrrace-uk/reports/maternal-report-2021/MBRRACE-UK_MaternaL_Report_2021_-_FINAL__-_WEB_VERSION.pdf.

8 Adlington K, Easter A, Galloway H, Howard LM. Mental health is neglected in maternal "near miss” research. BM/2022;376:e669486. doi: 10.1136/bmj-2021-069486 pmid: 35101865

9 Giles C. Covid-19: For the clinically extremely vulnerable, life hasn't returned to normal. BMJ 2022;376:0397. doi: 10.1136/bmj.0397 pmid: 35168939

10 Kamran F, Tang S, Otles E, etal. Early identification of patients admitted to hospital for covid-19 at risk of clinical deterioration: model development and multisite external validation study. BMJ 2022;376:e068576. doi: 10.1136/bmi-2021-068576 pmid: 35177406 